\title{
Openness to change and conservation in value-laden decisions
}

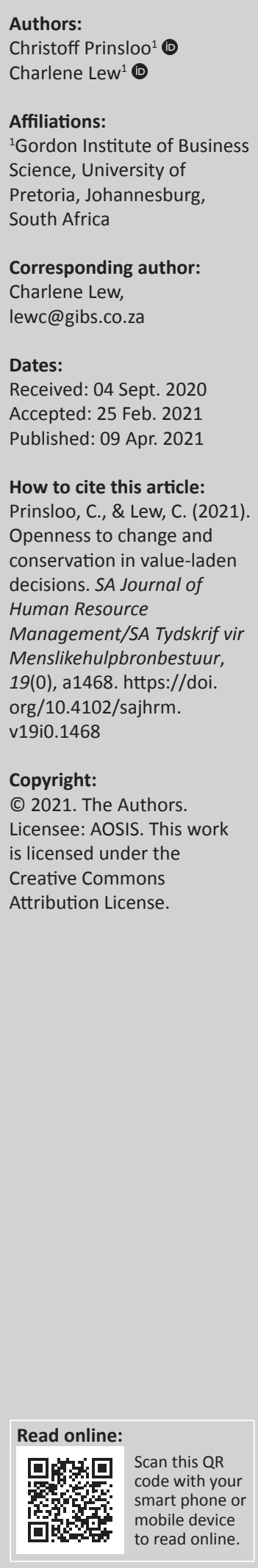

Orientation: Values influence decision-making in organisations; however, it is not yet clear how values of openness to change and conservation determine decision quality when managers are faced by competing values.

Research purpose: The research examines the relationships between managerial values of openness to change and conservation and cognitive decision quality.

Motivation for research: We argue that values influence cognitive decision-making quality.

Research approach/design and method: The quantitative research design made use of the portrait value questionnaire-based values of openness to change and conservation in relation to a measure of decision-making quality based on two value clashing decision scenarios.

Main findings: The results revealed that the managers' cognitive decision-making quality was lower for those who valued tradition within the conservation value block, with some indication that self-directed thought related to better cognitive processing of decision alternatives.

Contribution/value-add: The research demonstrates how the operationalised integrative complexity measure may be used as a novel decision-making quality metric. In addition, it introduces new value-sensitive decision-making scenarios. It also demonstrates that decision quality considerations in the value-driven decision-making dialogue are as important as ethical considerations. A values and quality decision-making framework gives managers an approach to higher quality decisions.

Practical/managerial implications: As values are stable rules of behaviour, the results support the development of decision-making quality and values awareness for managers.

Keywords: decision-making quality; managerial values; openness to change; conservation; value clashes.

\section{Introduction Orientation}

Management decision-making is an important business practice (Franklin, 2013) and is a core function of management itself (Baba \& HekenZadeh, 2012; Harrison \& Pelletier, 2000). Somewhere between skill (Lejarraga, Pachur, Frey, \& Hertwig, 2016), process (Seo, Lee, \& Lee, 2017) and intuitive art form (Hess, Quees, \& Patterson, 2012), it has been the topic of study for more than 60 years. Despite this, the problem of poor decision-making persists, often because of disparate viewpoints rooted in individual value systems (Ariail, Aronson, Aukerman, \& Khayati, 2015; Bazerman \& Moore, 2013; Fritzsche \& Oz, 2007).

The call for research on how individual-level values impact workplace outcomes has been evident for some time (Cohen \& Caspary, 2011). Literature has shown that managers' stable values influence human behaviour (Bilsky \& Schwartz, 1994; Rokeach, 1973) and play a significant role in decision-making (Lichtenstein, Lichtenstein, \& Higgs, 2017). Recently, Stephan (2020) reiterated the need for an understanding of the mechanisms through which values influence organisational behaviour.

We know that values inform ethical choice (Connor \& Becker, 2003; Fritzsche \& Oz, 2007); however, this relationship is complex (Hewlin, Dumas, \& Burnett, 2015; Shepherd \& Baron, 2013). Moreover, decision success or decision quality (Rausch \& Anderson, 2011; Seo et al., 2017) goes beyond ethical choice. Given that decision success holds the position of the sine qua non of good management' (Harrison \& Pelletier, 2000, p. 469), we proposed that managers' decision-making quality presents a significant and undervalued research variable in relation to values. 


\section{Research purpose and objectives}

Values act as guiding principles to yield coherence in our decisions across different situations (Schwartz, 1992). Yet, value differences are evident in contemporary society, reflected, for instance, in political upheavals and corporate scandals. It is not yet clear whether differences in the quality of decisions relate to managerial value sets when managers are faced with difficult choices. Difficult decisions include, for instance, when managers are faced with competing good or sacred drivers such as regarding the earth, equality of people, human life or authority. The research asks whether managers who embrace different value sets differ in the quality of the decisions they make in such circumstances. Specifically, this article sheds light on whether the quality of decisions differs between those managers who value conservation (conformity, tradition and security) and those who are open to change (self-direction and stimulation). Therefore, the objective of the study was to examine the relationships between managerial values of openness to change and conservation and cognitive decision quality for value-laden decisions.

\section{Literature review}

\section{Values: Conservation versus openness to change}

Values are 'enduring beliefs that a specific mode of conduct or end-state of existence is personally or socially preferable to an opposite or common mode of conduct or end-state of existence' (Rokeach, 1973, p. 5). To simplify, a manager's values dictate whether any behaviour or life outcome should be socially preferred over another. Schwartz's (1992) theory of universal values is most salient to understand people's views on 'what ought to be'. Schwartz's (1994) initial value map categorised 56 human values into 10 value-type groupings. An updated framework incorporates 19 values structured around two axes: self-enhancement versus selftranscendence and conservation versus openness to change (Schwartz et al., 2012). This research focused on the conservation and openness to change value axis.

Motivated partially to protect oneself and escape anxiety whilst having a social focus, managers who value conservation do so because of varying intensities of valuing interpersonal conformity, conformity to rules, tradition, societal security and personal security. In other words, the goal of conservation lies in a need to avoid actions that could upset or harm other people, to abide by the laws that govern and to preserve traditions embedded in religion, family or culture (Schwartz et al., 2012). Individuals who value conservation tend to have stable Big Five personality traits of agreeableness, conscientiousness, emotional stability, emotions of calmness and reduced fear (Tamir et al., 2016; Vecchione, Alessandri, Barbaranelli, \& Caprara 2011). The distinct facets of the conservation value set are conformity, or the 'restraint from actions, inclinations, and impulses likely to upset or harm others and violate social expectations or norms'; tradition, or 'respect, commitment, and acceptance of the customs and ideas that one's culture or religion provide'; and security, or 'safety, harmony, and stability of society, of relationships, and of self' (Schwartz, 1994, p. 22).

On the other side of the spectrum are individuals who are motivated by a calm or anxiety-free need to grow, whilst having a personal focus. A value set of openness to change encompasses the three values of self-directed thought, selfdirected action and stimulation (Schwartz et al., 2012). Managers living by openness to change values, specifically stimulation and self-direction, may display Big Five personality traits of openness and extraversion (Vecchione et al., 2011). The most desirable emotions for these managers are interest and excitement (Tamir et al., 2016). The distinct facets of this value set are stimulation or the 'excitement, novelty, and challenge in life', and self-direction or 'independent thought and action - choosing, creating, exploring' (Schwartz, 1994, p. 22).

\section{Values and organisational behaviour}

Former research shows that those who value conservation may more readily accept organisational change (Cohen \& Caspary, 2011). Within the value of openness to change, selfdirection may negatively impact new team processes such as team coherence, efficacy, and may increase conflict. In contrast within conservation, the value of security supports positive team processes (Woehr, Arciniega, \& Poling, 2013).

It may not be surprising that openness to change relates to political activism, whereas conservation does not (Vecchione et al., 2015). Openness to change may also entail lower propensity towards making decisions that support environmental sustainability, given a reduced focus on others (Grebitus, Steiner, \& Veeman, 2013). These examples do not suggest that openness to change consistently leads to negative organisational behaviour, as entrepreneurs are often motivated by the self-direction component of openness to change (Looi \& Kamarulzaman, 2015).

These examples from research in values theory suggest that emotions, values, decisions and behaviours interrelate in ways not yet fully understood. Although there are multiple examples in literature of how values determine behaviours in organisations, literature says very little about values and quality of decisions, other than from an ethical viewpoint.

\section{Values and decision-making}

An understanding of personal values provides a useful perspective on decision-making, with Schwartz's (1992) value framework, described above, being particularly relevant. Researchers have been interested in the relationship between personal values on the one hand and ethical decision-making (Fritzsche \& Oz, 2007), environmentally sensitive choices (Grebitus et al., 2013) and the selection of decision support systems (Ariail et al., 2015) on the other hand. Implicitly personal value systems play an important role in decision-making in as far as 'choice involves 
judgement, and judgement implies values' (Ariail et al., 2015, p. 137).

Organisational decision-making is often compromised when taboo or sacred topics, such as issues of religion, sexuality, human life or respect are avoided. One strategy to deal with such issues is reframing the taboo scenarios as trade-offs, where one sacred value is favoured at the expense of another (Schoemaker \& Tetlock, 2012). Shortland and Alison (2020) purport that in value clashes, a decision-maker will attempt to choose the least negative outcome, or 'least-worst outcome'. Routine trade-offs occur when having to decide between secular values, such as different organisational policies. When a single sacred value is dominant, the decision-maker is able to make taboo trade-offs. However, when both competing values are equally sacred, this may result in redundant deliberation and indecision.

\section{Good decisions}

The question of what constitutes quality in decision-making is often vague (Franklin, 2013), focusses on idealistic and perhaps synthetic 'true measure' comparisons (Boyle, Hanlon, \& Russo, 2012; Hess et al., 2012; Lejarraga et al., 2016) or employs cumbersome measurement techniques (Wanous \& Youtz, 1986).

Different paradigms define quality decisions in different ways. From an ethical decision-making perspective, good decisions refer to making the right moral choice. In managerial thinking, the power of analysis and decision-making processes may constitute quality decision-making (Dean \& Sharfman, 1996). This process perspective, in turn, rests on the notion that better access to data implies higher decision quality (Warnock \& Gantz, 2017).

Within this normative view of decision quality mathematical models, such as have been pioneered by Von Neumann and Morgenstern's formula, define quality decisions as those according to which the decision-maker seeks to maximise utility and fulfil assumptions of the weights and probabilities of decision options (Leonard, 1995). In addition to maximised utility, this rational decision-making view highlights good process and probability analysis as indicators of decision quality.

It seems that managers in practice regard decision outcomes as a better indicator of decision quality than 'science-based' procedural approaches (Arvai \& Froschauer, 2010). Kock and Gemünden (2016) linked decision quality to optimal rigour and rationality when decision-makers use 'more and better information' in decision processes. Citing Dean and Sharfman (1996) and Eisenhardt and Zbaracki (1992), they differentiated between decision effectiveness that require the achievement of a desired outcome, and decision quality that is not defined by the outcome (Kock \& Gemünden, 2016). In big data decision-making, a high-quality decision depends on the quality of inputs or information and the process to transform this into outputs. In business intelligence, quality decisions are characterised by problem-solving, alignment to risk preferences and the structure of the decision process (Visinescu, Jones, \& Sidorova, 2017). Management decisions require systemic, iterative, adaptive, self-correcting and innovative processes (Rausch \& Anderson, 2011). However, Franklin (2013) argued that the complexity of managerial decision contexts invalidates rational decision processes.

Neither good processes nor outcomes are adequate indicators of decision quality because poor decision processes may have good outcomes, and vice versa. Circumstantial coincidences, unconsidered factors, cognitive processes (Gino, Shu, \& Bazerman, 2010; White \& Poldrack, 2014) or simply blind luck may have greater impact than process in the decision outcomes.

\section{Measuring the quality of decisions as integrative complexity}

Given the shortcomings of different models of quality decisions, this research operationalises quality of decisions not in terms of process or outcomes, but in terms of the realtime cognitive processing of the decision itself. The concept of integrative complexity (Schroder, 1971) is significant and useful as a proxy for cognitive decision-making quality.

Tetlock (1986) operationally defined integrative complexity as the achievement of: (1) construct differentiation, which is the 'variety of aspects or components of an issue that a person recognises' (p. 822) when faced with a choice and (2) integration, which is the 'development of conceptual connections among differentiated constructs' (p. 822). Accordingly, high-quality decisions from a cognitive processing perspective are those choices that are more considered (higher levels of differentiation), and where the interactions of the various options are fully evaluated (higher levels of integration).

Considering different value orientations of managers in making decisions according to tradition or what society expects, versus following their own thinking and needs for stimulation, we may ask: 'When managers align themselves closer to social norms, would they also give more consideration to options in decisions where multiple value sets are at stake (conservationists)?' Or:

Are individuals who value their own goals and stimulation (openness to change) more likely to go through a rigorous cognitive processes when there are complexities in the values within a choice?

This leads to the hypothesis that there is a difference in the cognitive decision-making quality of those who value conservation and those who value change in situations where values are heightened because of internal tensions between them. The research suggests that those who are open to change will differentiate the aspects of the decision they consider and also integrate more connections amongst competing cues. Conversely, the research also suggests that 
those who value conforming to rules and society and tradition will be less effective in considering competing cues in the cognitive decision process:

Hypothesis 1: There is a positive relationship between openness to change and cognitive decision quality during value clashes.

Hypothesis 2: There is a negative relationship between conservation values and decision quality during value clashes.

Hypothesis 3: Individuals with higher levels of openness to change will make better quality decisions than individuals with lower levels of openness to change.

Hypothesis 4: Individuals with higher levels of conservation will make lower quality decisions than individuals with lower levels of openness to change.

\section{Research design \\ Research method and approach}

The study employed a quantitative research design that incorporated an assessment of values and a vignette-based task to code for cognitive decision quality. The data gathering strategy involved a single integrated online questionnaire, and the pilot study indicated a duration of 15 to $45 \mathrm{~min}$ to complete the assessment on a Qualtrics platform (Hewson \& Stewart, 2016).

\section{Research participants}

The sample was drawn from the management population of a large company within South Africa characterised by cultural diversity and resource shortages, an insurance company and a production company. This represented an ideal population to ensure value diversity. A total of 204 managers were included in the study with a response rate of $61 \%$. The majority of the sample $(67 \%)$ fell within the $30-50$-year-old age bracket. In terms of gender, $73 \%$ were male participants and $27 \%$ were female participants. Mother tongue classifications were of European descent - Afrikaans (42.2\%), of European descent - English (20.4\%), of Indian descent (7\%), of African descent - indigenous languages such as isiZulu, isiXhosa, Sesotho and others (26.4\%) and mixed race - Afrikaans (3.5\%).

\section{Measuring instruments}

In addition to demographic variables, the survey included a measure of values, two scenarios to measure value-sensitive situations and a measure of integrative complexity to indicate cognitive decision quality.

\section{Portrait value questionnaire}

The portrait value questionnaire (PVQ) (Schwartz et al., 2012) measures human values and has been tested on at least 55 samples, involving 11000 participants (Bilsky \& Schwartz, 1994; Schwartz et al., 2012). This test measures 19 value orientations through 57 items and yields a two-dimensional representation of an individual's personal value orientation. The research focused on the items for conservation (four items each for tradition and conformity and five items for security) and openness to change (four items for selfdirection and three items for stimulation). Typical items portrayed different values: It is important to him/her never to violate rules or regulations or It is important to him/her to take risks that make life exciting, giving participants the opportunity to compare the statements to themselves. The analysis included only the central values of openness to change and conservation.

\section{Scenarios for value-sensitive decision-making (context)}

Building on existing approaches (Ametrano, 2014; Fritzsche \& Oz, 2007; Hanselmann \& Tanner, 2008; Schoemaker \& Tetlock, 2012), scenarios were developed that (1) depicted a sacred value or secular value clash to increase the likelihood of value-driven decision-making and (2) exploited the tensions within the emerging market context to illustrate value permeability and resultant value clashes.

The first value clash scenario described a decision facing a South African municipal manager (mayor). Faced with limited funds, the manager was given the task of either appointing 20 additional teachers to address causes of recent poor education results, or alternatively to adhere to the demands of disgruntled municipal workers threatening labour action. The real-world context of the scenario elicits value conflicts linked to a flailing education system in the South African context. This scenario was changed for half the respondents by making it explicit that should the mayor choose to back the municipal workers, and his re-election would be virtually guaranteed. This reframing intensified the clash between valuing (1) community welfare through social upliftment and (2) personal gain and power.

The second scenario measured decision-making quality in a manufacturing firm. The respondents were compelled to make a decision based on a scenario with a clash between potential personal financial loss and the introduction of new anti-pollution technology. The scenario was reframed for half of the respondents to juxtapose potential harm against society or the community and environmental concerns.

The scenarios were admitted to three rounds of pilot testing that served to test the applicability thereof to the design criteria, and to receive feedback from the respondents regarding its believability and applicability to their contexts.

\section{Cognitive decision quality}

The integrative complexity measure required respondents to write a paragraph (taking $5 \mathrm{~min}$ or less) to motivate the decision based on the scenario (Tetlock, 1986). These texts are then coded and themed for construct differentiation and integration, using pre-developed integrative complexity guidelines (Baker-Brown et al., 1990). Contextual differentiation refers to the extent to which the subject is willing to incorporate alternative ways of looking at a decision problem. Lower scores reflect decision rigidity and adherence to decision rules, a dichotomous predisposition 
towards the process and unwillingness to be open to alternative solutions. In contrast, higher scores are indicative of openness to alternative interpretations of decision cues and less stringent adherence to decision rules. Integration coding assesses the extent to which the subjects applied decision flexibility and openness to multiple alternatives in the decision-making process, specifically in that low scores indicate few conceptual connections between decision options, whereas higher level scores indicate propensity to link, compare, contrast and synthesise alternative solutions from various interpretations of the decision situation (Tetlock, 1986). Based on correlations between hand- and computercoded decision quality scores (Conway, Conway, Gornick, \& Houck, 2014), combined coding scores were used as the average of the two scores equally weighted.

\section{Statistical analysis}

Cronbach' alpha scores were calculated for the dimensions of the PVQ (Schwartz et al., 2012). The effectiveness of the decision scenarios was assessed in terms of discriminatory value, levels of value clash of discomfort produced and decision sureness. Firstly, based on a yes or no split, the scenarios sufficiently elicited value disagreement to indicate the presence of a value clash during the decision-making process. Secondly, measures of discomfort and uncertainty were calculated for the scenarios. Pearson's correlation scores for integrative complexity (decision quality) were calculated to indicate correlations between the hand-coded and computer-coded data.

A combination of value orientation plots with t-tests, Pearson's correlations, linear regression analyses, decision tree analyses and t-tests were used given the complexity of scenario-specific decision-making. The value orientation plots were used to indicate any demographic differences in values. The correlation and linear regression analyses were employed to show initial relations and predictions of values and decision quality. Decision tree analyses (using the Chisquare Automatic Interaction Detector (CHAID) algorithm, that indicates the optimal relationship configuration between variables to predict an outcome) have been shown to be particularly robust in assessing data sets with multiple variables with complex and non-linear relationships (Patel \& Rana, 2014), and offered a further predictive model of decision quality as a dependent variable. This multiple variable methodology was also shown to be beneficial in analysis for its power in variable screening, comprehensiveness and ease of interpretation (He, Wang, Zang, \& Cook, 2013; Milanovic \& Stamenkovic, 2016).

The analysis also included recursive partitioning used in decision tree analysis (Milanovic \& Stamenkovic, 2016) to classify heterogeneous data into subsets of homogenous data groups, as this better reflects the trade-off process people apply when making decisions. As a result, the CHAID algorithm could indicate the core contributors to decisionmaking quality for the scenarios. Thereafter, independent $\mathrm{t}$-tests were used to calculate the differences between the qualities of decisions of managers scoring lower and higher on the value sets.

\section{Ethical considerations}

Ethical clearance for the research was obtained via the (associated university's) Research Ethics Committee. Data gathering followed ethical principles and ethical clearance approval, ensuring voluntary participation and the anonymity of respondents. Ethical Clearance number: DREC30032015-9417729.

\section{Results}

The PVQ measure was reliable for this sample for openness of change ( $\alpha=0.77)$ and conservation $(\alpha=0.86)$ values. For the education versus worker demand scenario, a $76 / 23 \%$ split between yes and no for educational service delivery over labour harmony indicated the presence of value disagreement, and $88 \%$ of respondents were comfortable and $97 \%$ were very or fairly sure about their decision. The personal or societal gain versus environment scenario elicited a value clash too, with a $74 / 26 \%$ agreement or disagreement for purchasing environmental saving technology at the cost of personal or societal gain. This indicated the validity of the measure to elicit a value clash. Significant Pearson's correlation scores between the hand-coded and computercoded data of decision quality $(r=0.53, p<0.00)$ compared favourably with correlations $(r=0.4$ and $r=0.6)$ for prior use of these tests (Conway et al., 2014).

The descriptive statistics for the sample appear in Table 1.

Figure 1 relates four specific value orientations plots, each for a different demographic group. The value plots indicate no significant general differences between the average value orientations based on gender, age, cultural group and

TABLE 1: Descriptive statistics.

\begin{tabular}{|c|c|c|c|c|c|c|c|c|c|c|}
\hline Variables & $\begin{array}{c}\text { Self-directed } \\
\text { thought } \dagger\end{array}$ & $\begin{array}{c}\text { Self-directed } \\
\text { action } \dagger\end{array}$ & Stimulation $\dagger$ & Tradition $\dagger$ & $\begin{array}{c}\text { Security } \\
\text { (personal) } \dagger\end{array}$ & $\begin{array}{l}\text { Security } \\
\text { (social) } \dagger\end{array}$ & $\begin{array}{c}\text { Conforming } \\
\text { (rules) } \dagger\end{array}$ & $\begin{array}{c}\text { Conforming } \\
\text { (interpersonal) } \dagger\end{array}$ & $\begin{array}{c}\text { Decision quality } \\
\text { scenario } 1 *\end{array}$ & $\begin{array}{c}\text { Decision quality } \\
\text { scenario } 2 *\end{array}$ \\
\hline Mean & 0.31 & 0.07 & -0.04 & -0.47 & 0.48 & 0.45 & 0.53 & -0.88 & 4.23 & 4.48 \\
\hline SD & 0.78 & 0.76 & 0.68 & 1.22 & 0.58 & 0.63 & 0.70 & 1.18 & 1.02 & 0.89 \\
\hline Kurtosis & 0.31 & 0.68 & 0.75 & -0.45 & 0.59 & 0.86 & 1.15 & -0.64 & -0.30 & 0.24 \\
\hline Skewness & -0.59 & -0.61 & -0.06 & -0.06 & -0.73 & -0.75 & -0.62 & -0.16 & 0.70 & 0.59 \\
\hline Range & 3.93 & 4.47 & 4.51 & 5.67 & 3.33 & 3.63 & 4.46 & 5.16 & 4.23 & 4.48 \\
\hline
\end{tabular}

SD, standard deviation.

$N=204$.

$\dagger$, Six-point Likert scale ranging from very much like me to not like me at all.

$\$$, Range from 1 to 7 . 


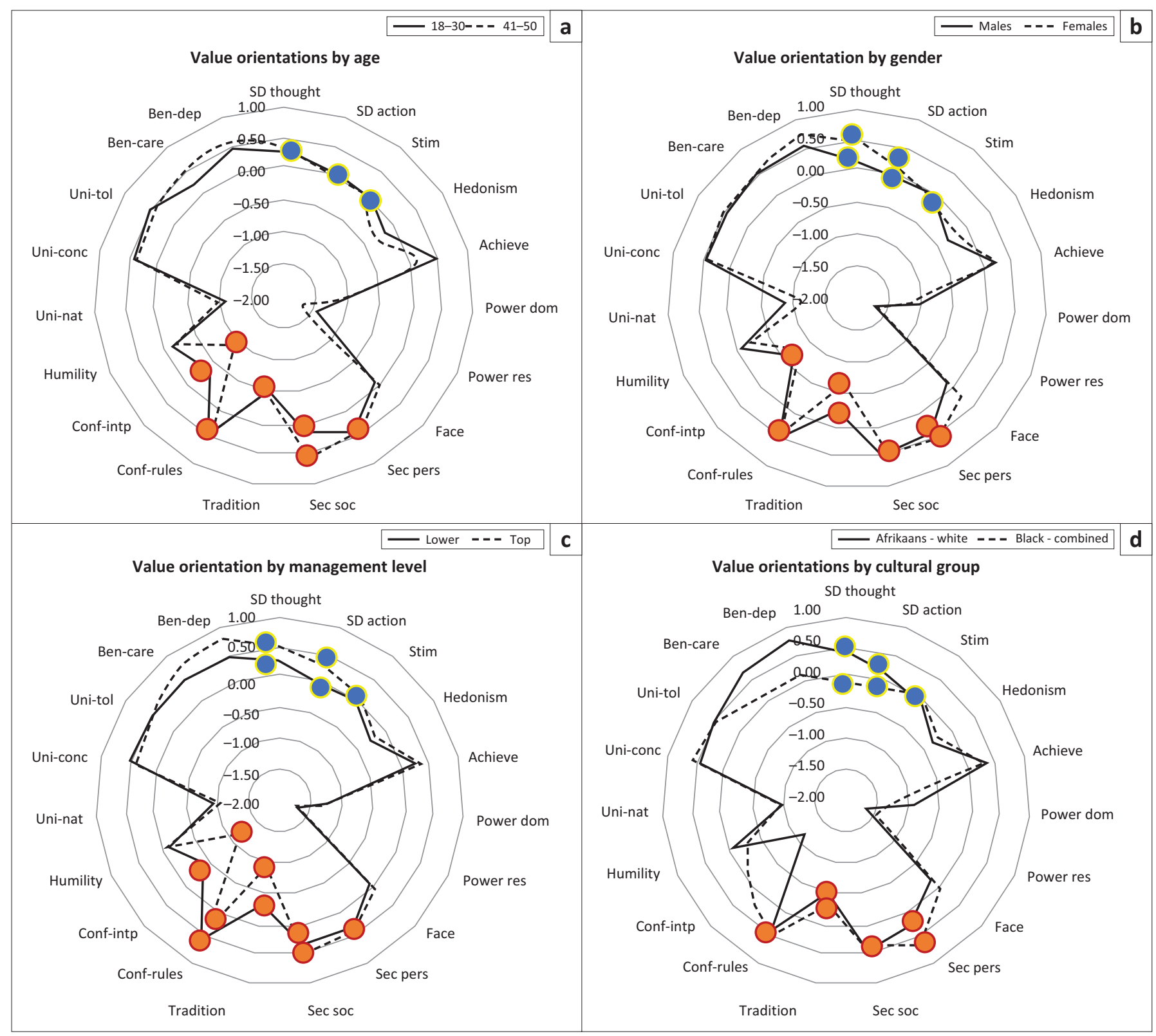

SD, Self-directed.

FIGURE 1: Value orientations and demographic groupings; (a) value orientations by age; (b) value orientation by gender; (c) value orientation by management level; (d) value orientations by cultural group.

managerial level. Cultural differences were more acute for this sample on the value of interpersonal conformity.

Lower $t$-test scores appear for the tradition component of conservation for the younger over older participants $(-0.50$ versus $-0.36, p<0.05)$, and for females over males ( -0.69 versus $-0.23, p<0.05)$. Interpersonal conformity, which together with conformity to rules make up the conformity dimension of conservation, was valued higher by those who speak indigenous languages over those who speak Afrikaans (0.08 vs. $-1.14, p<0.05)$ and lower levels of management over top management $(-0.42$ vs. $-1.19, p<0.05)$. The top management group displayed a preference for self-directed thought and action (a component of openness to change) instead.

In the service delivery-labour harmony value clash (scenario $1)$, more female participants $(83 \%)$ than male participants
(73\%) and more top managers $(81 \%)$ than middle managers $(75 \%)$ were in favour of the appointment of teachers. Most supportive of educational service delivery was the 31-40-year age group (83\%), and least supportive were those over the age of $50(65 \%)$. The participants displayed higher decision quality for the unframed scenario $(M=3.87, \mathrm{SD}=1.55)$ than the framed scenario, $(t[203]=35.56, p=0.00)$. In the value clash between curbing environmental impact and financial interest of the firm (scenario 2), the framing that included only personal gain was indicative of higher levels of consideration during decision-making $(M=3.94, \mathrm{SD}=1.31)$ than the framed scenario that included financial value for the firm, $(t[203]=43.04, p=$ 0.00 ). The majority of all the demographic groups were in favour of investment in the technology.

In terms of the relationships amongst the variables, Table 2 indicates that only one of the values significantly related to 
TABLE 2: Pearson's correlation results.

\begin{tabular}{|c|c|c|c|c|c|c|c|c|c|}
\hline Variables & $\begin{array}{l}\text { Self-directed } \\
\text { thought }\end{array}$ & $\begin{array}{l}\text { Self-directed } \\
\text { action }\end{array}$ & Stimulation & Tradition & $\begin{array}{l}\text { Security } \\
\text { (personal) }\end{array}$ & $\begin{array}{l}\text { Security } \\
\text { (social) }\end{array}$ & $\begin{array}{c}\text { Conforming } \\
\text { (rules) }\end{array}$ & $\begin{array}{c}\text { Conforming } \\
\text { (interpersonal) }\end{array}$ & $\begin{array}{l}\text { Decision quality } \\
\text { (scenario 1) }\end{array}$ \\
\hline Self-directed action & $0.440 * *$ & - & - & - & - & - & - & - & - \\
\hline Stimulation & -0.013 & 0.014 & - & - & - & - & - & - & - \\
\hline Tradition & $-0.378 * *$ & $-0.357 * *$ & -0.032 & - & - & - & - & - & - \\
\hline Security (personal) & -0.069 & -0.099 & $-0.343 * *$ & -0.024 & - & - & - & - & - \\
\hline Security (social) & -0.068 & -0.102 & -0.072 & 0.081 & 0.075 & - & - & - & - \\
\hline Conforming (rules) & $-0.228 * *$ & $-0.282 * *$ & $-0.261 * *$ & 0.042 & $0.325 * *$ & 0.076 & - & - & - \\
\hline Conforming (interpersonal) & $-0.319 * *$ & $-0.246 * *$ & $-0.189 * *$ & 0.111 & $0.173^{*}$ & $-0.161^{*}$ & 0.066 & - & - \\
\hline Decision quality (scenario 1) & 0.049 & 0.070 & 0.055 & $-0.212 * *$ & 0.004 & -0.039 & 0.065 & 0.014 & - \\
\hline Decision quality (scenario 2) & 0.078 & 0.049 & 0.009 & $-0.161^{*}$ & -0.008 & -0.004 & -0.016 & -0.011 & $0.661 * *$ \\
\hline
\end{tabular}

$N=204$.

$*, p<0.05$ (two-tailed).

$* *, p<0.00$ (two-tailed)

TABLE 3: Linear regression results for the values and decision quality.

\begin{tabular}{|c|c|c|c|c|c|c|}
\hline \multirow[t]{2}{*}{ Variables } & \multicolumn{3}{|c|}{ Decision quality scenario 1} & \multicolumn{3}{|c|}{ Decision quality scenario 2} \\
\hline & $B$ & SE $B$ & $\beta$ & $B$ & SE $B$ & $\beta$ \\
\hline Self-directed thought & 0.12 & 0.10 & 0.09 & 0.01 & 0.09 & 0.01 \\
\hline Self-directed action & -0.03 & 0.11 & -0.02 & 0.03 & 0.09 & 0.03 \\
\hline Stimulation & 0.00 & 0.11 & 0.00 & -0.06 & 0.09 & -0.04 \\
\hline$R^{2}$ adjusted & - & - & -0.007 & - & - & -0.012 \\
\hline$F$ change & - & - & 0.498 & - & - & 0.0196 \\
\hline Tradition & -0.13 & 0.06 & $-0.16 *$ & -0.20 & 0.05 & $-0.27 * *$ \\
\hline Security (personal) & 0.07 & 0.13 & 0.04 & 0.00 & 0.11 & 0.00 \\
\hline Security (social) & 0.03 & 0.12 & 0.02 & 0.13 & 0.10 & 0.09 \\
\hline Conforming (rules) & -0.08 & 0.11 & -0.06 & 0.01 & 0.09 & 0.01 \\
\hline $\begin{array}{l}\text { Conforming } \\
\text { (interpersonal) }\end{array}$ & -0.01 & 0.06 & -0.01 & 0.06 & 0.05 & 0.08 \\
\hline$R^{2}$ adjusted & - & - & 0.004 & - & - & 0.078 \\
\hline$F$ change & - & - & 1.1178 & - & - & $3.304 *$ \\
\hline
\end{tabular}

SE B, standard error; B, unstandardised beta coefficient; $\beta$, standardised beta coefficient.

$N=204$.

$*, p<0.05$.

$* *, p<0.01$.

decision quality, namely a negative relationship between tradition values and decision quality for scenario $1, r(202)=$ $-0.212, p<0.001$, and scenario $2, r(202)=-0.161, p<0.05$. The hypotheses of the relationships between the value blocks and decision quality could therefore not be accepted (Hypotheses 1 and 2). However, the finding that tradition values relate to decision quality is significant. Table 3 echoes these findings in as far as tradition was shown to significantly predict lower decision quality for scenario $1, \beta=-0.16, t(5)=$ $-3.90, p<0.001$ and scenario $2, \beta=-0.16, t(5)=-3.90$, $p<0.001$, but only $2.5 \%$ of the variance in decision quality was explained by tradition values. The conservation value block significantly predicted lower decision quality for the financial gain versus environmental investment scenario at the $5 \%$ level of significance, yielding partial support for Hypothesis 2.

When confronted by a clash between service delivery and maintenance of labour harmony, the decision tree analysis confirmed the significance of the tradition value on lower decision quality $(M=2.8, \mathrm{SD}=1.1$ vs. $M=2.4, \mathrm{SD}=1.0$, $p=0.00$, split around a tradition value of -0.3 ) as per Figure 2. Gender came into play for the more traditionally orientated male participants who scored lower than female participants on decision quality $(M=2.4, \mathrm{SD}=0.9$ vs.

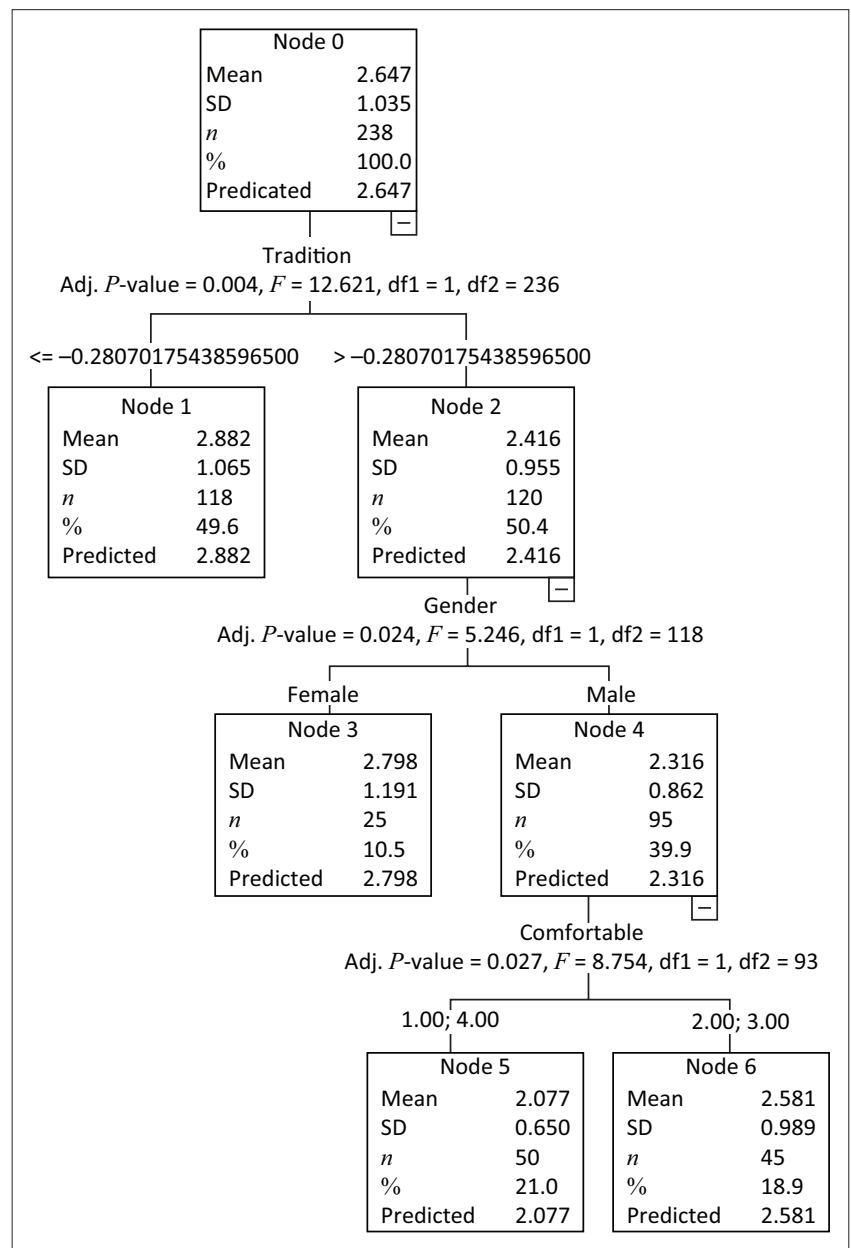

SD, standard deviation.

FIGURE 2: Decision tree analysis for the tradition value in conservation for scenario 1.

$M=2.8, p<0.05)$. Decision comfort also featured with the respondents most comfortable with their decision-making displaying lower quality decisions $(M=2.1, \mathrm{SD}=0.7$ vs. $M=$ $2.6, \mathrm{SD}=1.0, p<0.05)$. The results show that the lower quality decisions were made by tradition-oriented male participants, most comfortable with their decisions $(M=2.1$, $\mathrm{SD}=0.7)$.

When participants were confronted by a clash between financial interests and investment in the environment 
TABLE 4: The $t$-test results for decision-making quality and value blocks.

\begin{tabular}{|c|c|c|c|c|c|c|}
\hline Value block & $M$ & Variance & Observations & $d f$ & $t$-stat & $p$ (two-tail) \\
\hline Opposing conservation & 2.79 & 1.10 & 93 & 236 & -2.87 & 0.00 \\
\hline Favouring conservation & 2.40 & 0.86 & 145 & - & - & - \\
\hline Open to change & 2.75 & 1.08 & 144 & - & - & - \\
\hline Not traditional & 2.88 & 1.15 & 116 & 236 & 3.40 & 0.00 \\
\hline Traditional & 2.43 & 0.91 & 122 & - & - & - \\
\hline $\begin{array}{l}\text { Not self-directed } \\
\text { (thought) }\end{array}$ & 2.51 & 1.11 & 116 & 236 & -2.02 & 0.04 \\
\hline Self-directed (thought) & 2.78 & 1.01 & 122 & - & - & - \\
\hline
\end{tabular}

(scenario 2), a different configuration of factors was found. The decision tree analysis still showed the predictive value of tradition, with the lowest traditional scores predicting higher decision quality $(M=3.05, \mathrm{SD}=$ 0.96, $p=0.00)$. However, in this scenario, introducing societal financial interests increased decision quality significantly $(M=2.81, \mathrm{SD}=0.83$ vs. $M=3.25, \mathrm{SD}=1.03$, $p<0.05)$.

Thet-test results comparing the decision quality of the openness to change and conservation values groups in Table 4 suggest support for Hypotheses 3 and 4 . The 145 managers with higher conservation value scores $(M=2.40$, $\mathrm{SD}=0.94)$ had lower decision-making scores than the 93 managers opposing conservation $(M=2.79, \mathrm{SD}=1.10)$, $t[236]=-2.87, p=0.00)$. This occurred when splitting the population at a conservation score of 0.1 .

Managers with higher openness to change value orientations ( $n=144)$ exhibited higher decision-making quality scores $(M=2.75, \mathrm{SD}=1.08)$ compared to those with low scores for this value set $(n=94, M=2.48, \mathrm{SD}=0.94),(t[236]=2.05$, $p=0.04)$ when the population was split at an openness to change value of 0.08 .

Taking the analysis at a lower level, two individual values played a significant role in predicting decision-making quality. The value of tradition, a subset of the conservation value block, showed a similar relationship with decisionmaking quality, with the 116 managers with low tradition values $(M=2.43, \mathrm{SD}=0.91)$ obtaining higher decision-making scores than the 122 managers with high traditional values $(M=2.88, \mathrm{SD}=1.15),(t[236]=3.40, p=0.00)$. Concurrently, managers with the value of self-directed thought $(n=116)$, a subset of the openness to change value block, made higher quality decisions $(M=2.78, \mathrm{SD}=1.01)$ than the 122 managers with low scores for this value $(M=2.51, \mathrm{SD}=1.11)$, $(t(236)=-2.02, p=0.04)$.

\section{Discussion}

The research examined whether managers who valued openness to change made better quality decisions than those who valued conservation when faced by value clashes. Decision quality was defined as conceptual recognition and integration of multiple constructs in the decision task.
Overall, the results led to the rejection of the hypotheses that a model of value blocks will predict cognitive decision quality, but with some indication that conservation values negatively predict decision quality. However, the results show that a value such as tradition can negatively impact decision quality. This finding is scenario-specific as different variables come to play in the cognitive processing of valueladen decisions.

The results support the hypotheses that higher or lower levels of conservation values and openness to change values relate to decision quality. Specifically, lower quality decisions are associated with higher traditional values and higher quality decisions with self-directed thought. In other words, the research showed that in a heightened value situation, we can predict that decision-makers with conservation values (valuing security and traditions) may make less considered decisions, particularly because of traditional values. Traditional values are associated with being devout, moderate, detached and respecting tradition (Schwartz, 1994, p. 31). Decision makers more open to change than their counterparts who oppose change make more considered decisions. Within the value block of openness to change are decision-makers who value stimulation, such as an exciting, varied or daring life, as well as those who are self-directed and therefore enjoy freedom, independence, curiosity, creativity, their own goals and self-respect (Schwartz, 1994, p. 31). According to the results, it is particularly self-directed thought, or valuing the freedom to nurture one's own ideas and abilities (Schwartz, 2012) that relates to taking decisions that are less constrained by decision rules and limited alternatives.

Whilst literature has shown that the supportive role values could play in improving sophisticated decision support systems (Ariail et al., 2015) and addressed the personal value versus professional value conflict in ethical decision-making (Ametrano, 2014), the link between personal values and cognitive decision quality has been neglected till now. Whilst Fritzsche and Oz (2007) expected a positive relationship between traditional (conserving) values and decision ethicality and a negative relationship between openness to change and decision ethicality, they found the opposite. Our study shows a negative relationship between decision quality and conservation (traditional values), comments on the Fritzsche and $\mathrm{Oz}$ (2007) findings by underlining the 


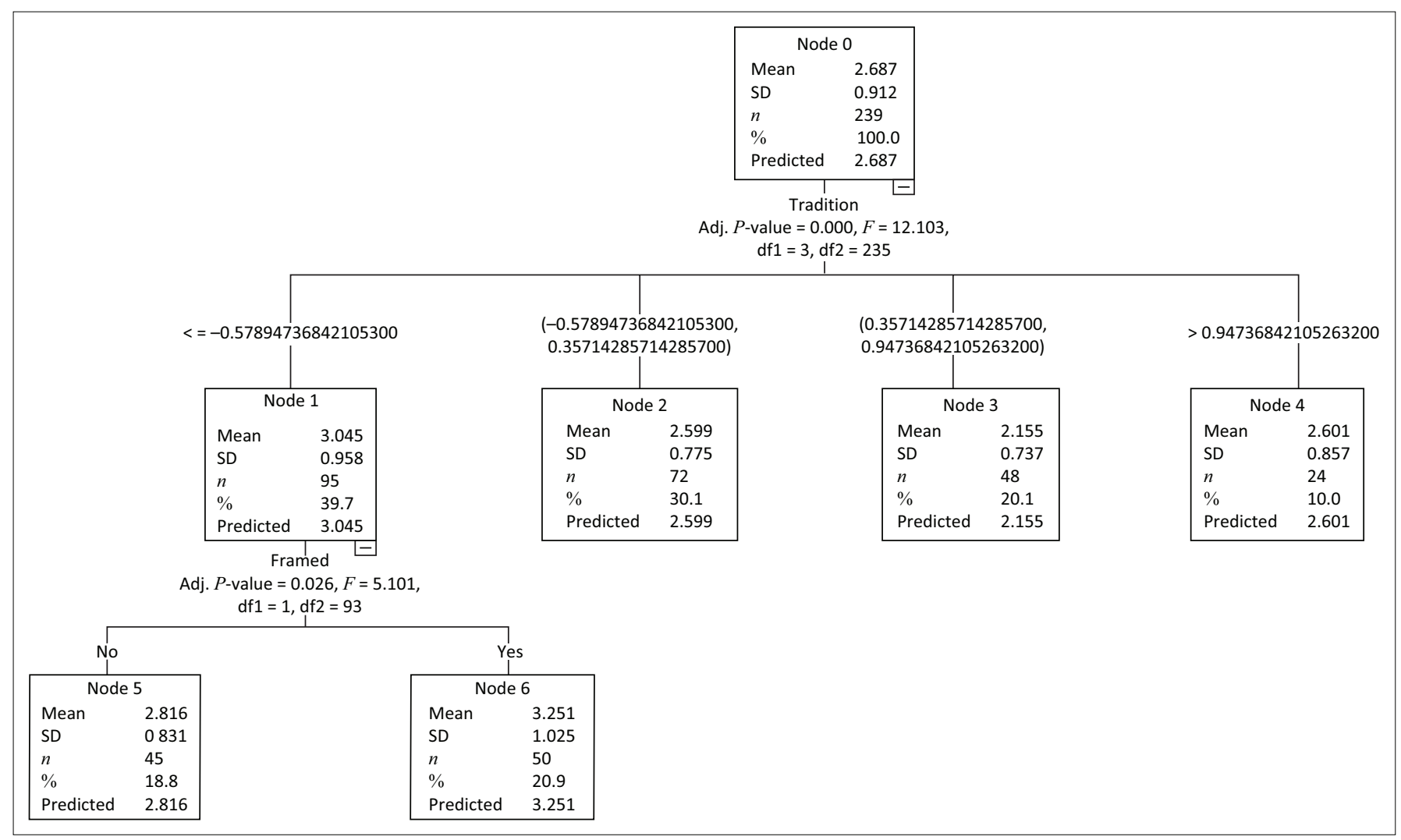

SD, standard deviation.

FIGURE 3: Decision tree analysis for the tradition value in conservation for scenario 2.

importance of values in decision-making and, more importantly, adding a further proxy for decision quality evaluation.

Although studies targeting decision-making quality have in the past been forced to adopt idealised target variables (Boyle et al., 2012; Hess et al., 2012; Lejarraga et al., 2016), elaborate attribute calculations (Wanous \& Youtz, 1986), or have strayed into unspecified metrics for quality (Franklin, 2013), this study presents a workable cognitive decision quality measure. It offers a way to employ integrative complexity (Tetlock, 1986) as an indicator of the quality of the actual decision, building on previous applications of the instrument (Baker-Brown et al., 1990).

\section{Practical implications}

The findings highlight important considerations for human resource practitioners. Managers are constantly faced by adaptive challenges in an increasingly complex work environment (Uhl-Bien \& Arena, 2018). Moreover, they need to make decisions where values compete, such as when both labour and societal needs have to be taken into account, or environmental preservations are at odds with the need to conserve finances. This calls for strategies to develop decision-making skills according to which managers will internalise the complexity of the decision situation, understand the competing values and consider the influence of their own values, in order to be more open to multiple possibilities. Especially at top-level management, where greater ambiguity is expected, there is a need for managers to overcome tendencies to conform. Instead, top managers need to be selected and developed to be open to flexible considerations of decision options and need to grow in the ability to integrate these intelligently whilst remaining open to change. This is particularly relevant when faced by competing but significant options or value clashes, such as drivers for social welfare competing with personal needs.

To improve the quality of decisions in organisations, human resource practitioners could develop systems and policies that reward creative and independent thinking. Management teams could be assisted to develop their cognitive complexity capabilities by encouraging them to find alternative ways of looking at decision problems. When value clashes arise, processes could be implemented to balance the tensions and derive value from different perspectives before decisions are made.

Figure 4 proposes a decision framework that incorporates consideration of contextual values embedded in the decision situation, personal values, differentiated preferences of multiple stakeholders and integrative solutions. The framework may be used to challenge managers to open thinking when making complex valueladen decisions. 


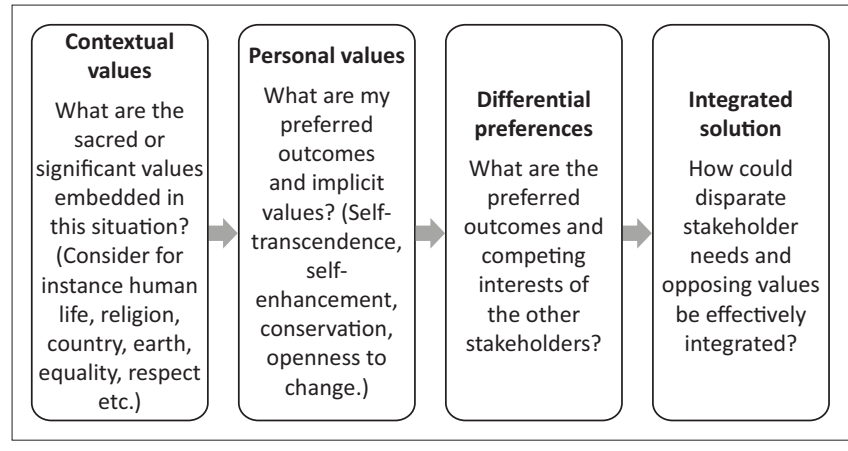

FIGURE 4: Decision-making framework for value-laden decisions.

\section{Limitations and recommendations}

The current study has some limitations. The findings relate to specific scenarios and different results may appear with the use of new vignettes. A large proportion of the sample was male participants, and a more heterogeneous sample would have been preferred. Moreover, the study followed a cross-sectional design and the research setting relied on a single cultural context. The results only begin to elucidate the personal antecedents of cognitive decision quality. Future work should target additional value blocks, alternative personal attributes (such as risk propensities) and environmental or circumstantial aspects of the scenarios to create better predictive models of cognitive decision quality. Different perspectives of decision theory lay emphasis on different facets of decision quality. Moving away from moral, outcomes and process-based indicators thereof, this research focused specifically on the cognitive processing of conflicting values to make a decision that takes multiple cues into account and that integrates multiple decision alternatives. The focus on a quality measure of decisionmaking, rather than a normative or ethical perspective, contributes to a richer understanding of values theory in decision-making. Further work can explore other dimensions of information and value processing in decision-making.

\section{Conclusion}

Within the context of organisational decision-making, the research found that tradition, a conservation value, negatively predicts decision quality, and harbouring the value of selfdirected thought encourages considered decisions in valueladen circumstances. Managers with low tradition values or high self-directed thought values are likely to better process the complexity of value-laden decision clashes. The newly created decision-making scenarios in this research give further insight into the context-specific impact of value clashes on decision-making quality.

\section{Acknowledgements}

The authors would like to thank the participants of this research project.

\section{Competing interests}

The authors declare that there have been no personal relationships or financial incentives that inappropriately influenced them in writing this article.

\section{Authors' contributions}

C.P. conducted the research as part of doctoral studies under the supervision of C.L. C.L. co-authored the article.

\section{Funding information}

This research received no specific grant from any funding agency in the public, commercial or not-for-profit sectors.

\section{Data availability}

Data are available in a separate repository upon request from the corresponding author.

\section{Disclaimer}

The views and opinions expressed in this article are those of the authors and do not necessarily reflect the official policy or position of any affiliated agency of the authors.

\section{References}

Ametrano, I.M. (2014). Teaching ethical decision making: Helping students reconcile personal and professional values. Journal of Counseling and Development, 92(2), 154-161. https://doi.org/10.1002/j.1556-6676.2014.00143.x

Ariail, D.L., Aronson, J.E., Aukerman, R., \& Khayati, A. (2015). Support for the inclusion of personal value preferences in decision support. Journal of Management Information and Decision Science, 18(1), 123-143.

Arvai, J.L., \& Froschauer, A. (2010). Good decisions, bad decisions: The interaction of process and outcome in evaluations of decision quality. Journal of Risk Research, 13(7), 845-859. https://doi.org/10.1080/13669871003660767

Baba, V.V., \& HakemZadeh, F. (2012). Toward a theory of evidence based decision making. Management Decision, 50(5), 832-867. https://doi.org/ 10.1108/00251741211227546

Baker-Brown, G., Ballard, E.J., Bluck, S., De Vries, B., Suefeld, P., \& Tetlock, P.E. (1990). Coding manual for conceptual/intergative complexity. Berkeley, CA: University of British Columbia and University of California.

Bazerman, M., \& Moore, D. (2013). Judgment in managerial decision making. NJ: John Wiley and Sons.

Bilsky, W., \& Schwartz, S.H. (1994). Values and personality. European Journal of Personality, 8(3), 163-181. https://doi.org/10.1002/per.2410080303

Boyle, P.J., Hanlon, D., \& Russo, J.E. (2012). The value of task conflict to group decisions. The Journal of Behavioral Decision Making, 25(1), 217-227. https:// doi.org/10.1002/bdm.725

Cohen, A., \& Caspary, L. (2011). Individual values, organizational commitment, and participation in a change: Israeli teachers' approach to an optional educational reform. Journal of Business \& Psychology, 26(3), 385-396. https://doi.org/ 10.1007/s10869-010-9186-1

Connor, P.E., \& Becker, B.W. (2003). Personal value sytems and decision making styles of public managers. Public Personnel Management, 32(1), 155-180. https://doi. org/10.1177/0306307017719702

Conway, L.G., Conway, K.R., Gornick, L.J., \& Houck, S.C. (2014). Automated integrative complexity. Political Psychology, 35(5), 603-624. https://doi.org/10.1111/ pops.12021

Dean, J.W., \& Sharfman, M.P. (1996). Does decision process matter? A study of strategic decision making effectiveness. Academy of Management Journal, 39(2), 368-396. https://doi.org/10.2307/256784

Eisenhardt, K.M., \& Zbaracki, M.J. (1992). Strategic decision making. Strategic Management Journal, 13(S2), 17-37. https://doi.org/10.2307/2486364

Franklin, C.L. (2013). Developing expertise in management decision making. Academy of Strategic Management Journal, 12(1), 21-38.

Fritzsche, D.J., \& Oz, E. (2007). Personal values' influence on the ethical dimension of decision making. Journal of Business Ethics, 75(4), 335-343. https://doi. org/10.1007/s10551-006-9256-5

Gino, F., Shu, L.L., \& Bazerman, M.H. (2010). Nameless + harmless = blameless: When seemingly irrelevant factors influence judgment of (un)ethical behavior. Organizational Behavior \& Human Decision Processes, 111(2), 93-101. https:// doi.org/10.1016/j.obhdp.2009.11.001

Grebitus, C., Steiner, B., \& Veeman, M. (2013). Personal values and decision making: Evidence from environmental footprint labeling in Canada. American Journal of Agricultural Economics, 95(2), 397-403. https://doi.org/10.1093/ajae/aas109

Hanselmann, M., \& Tanner, C. (2008). Taboos and conflicts in decision making: Sacred values, decision difficulty, and emotions. Judgment and Decision Making, 3(1), 51-63. 
Harrison, E.F., \& Pelletier, M.A. (2000). The essence of management decision Management Decision, 38(7), 462-470. https://doi.org/10.1108/002517496 10106972

He, S., Wang, G.A., Zang, M., \& Cook, D.F. (2013). Multivariate process monitoring and fault identification using multiple decision tree classifiers. International Journal of Production Research, 51(11), 3355-3371. https://doi.org/10.1080/00207543. of Production

Hess, T.M., Quees, T.L., \& Patterson, T.R. (2012). To deliberate or not to deliberate: Interactions between age, task characteristics, and cognitive activity on decision
making. Journal of Behavioral Decision Making, 25(1), 29-40. https://doi. org/10.1002/bdm.711

Hewlin, P., Dumas, T., \& Burnett, M. (2015). To thine own self be true? Facades of conformity, values incongruence, and the magnifying impact of leader integrity. Academy of Management Journal, 60(1), 178-199. https://doi.org/10.5465/ amj.2013.0404

Hewson, C., \& Stewart, D.W. (2016). Internet research methods. London: John Wiley and Sons Ltd.

Kock, A., \& Gemünden, H.G. (2016). Antecedents to decision making quality and agility in innovation portfolio management. Journal of Product Innovation Management, 33(6), 670-686. https://doi.org/10.1111/jpim.12336

Lejarraga, T., Pachur, T., Frey, R., \& Hertwig, R. (2016). Decisions from experience: From monetary to medical gambles. Journal of Behavioral Decision Making, 29(1), 67-77. https://doi.org/10.1002/bdm.1877

Leonard, R.J. (1995). From parlor games to social science: Von Neumann, Morgenstern, and the creation of game theory 1928-1944. Journal of Economic Literature, 33(2), 730-761. https://doi.org/10.2307/2729025

Lichtenstein, S., Lichtenstein, G., \& Higgs, M. (2017). Personal values at work: A mixed-methods study of executive's strategic decision-making. Journal of Genera Management, 43(1), 15-23. https://doi.org/10.1177/0306307017719702

Looi, K., \& Kamarulzaman, Y. (2015). Convergence in the priorities of entrepreneurial values: Empirical evidence from Malaysia. Journal of International Entrepreneurship, 13(1), 67-88. https://doi.org/10.1007/s10843-014-0136-2

Milanović, M., \& Stamenković, M. (2016). CHAID decision tree: Methodological frame and application. Economic Themes, 54(4), 563-586. https://doi.org/10.1515/ ethemes-2016-0029

Patel, B.R., \& Rana, K.K. (2014). A survey on decision tree algorithm for classification International Journal of Engineering Development and Research, 2(1), 1-5.

Rausch, E., \& Anderson, C. (2011). Enhancing decisions with criteria for quality Management Decision, 49(5), 722-733. https://doi.org/10.1108/0025174111 1130814

Rokeach, M. (1973). The nature of human values. New York, NY: Free Press.

Schoemaker, P.J.H., \& Tetlock, P.E. (2012). Taboo scenarios: How to think about the unthinkable. California Management Review, 54(2), 5-24. https://doi.org/ 10.1525/cmr.2012.54.2.5

Schroder, H.M. (1971). Conceptual complexity and personality organization. In H.M. Schroder \& M.J. Driver (Eds.), Personality theory and information processing H.M. Schroder \& M.J. Driver (Eds.), Personaly
(pp. 240-273). New York, NY: Ronald Press.

Schwartz, S.H. (1992). Universals in the content and structure of values: Theoretical advances and empirical tests in 20 countries. Advances in Experimental Socia Psychology, 25, 1-65. https://doi.org/10.1016/S0065-2601(08)60281-6
Schwartz, S.H. (1994). Are there universal aspects in the structure and contents of human values? Journal of Social Issues, 50(4), 19-45. https://doi.org/10.1111/ j.1540-4560.1994.tb01196.x

Schwartz, S.H., Cieciuch, J., Vecchione, M., Davidov, E., Fischer, R., Beierlein, C., ... Dirilen-Gumus, O. (2012). Refining the theory of basic individual values. Journal of Personality and Social Psychology, 103(4), 663-688. https://doi.org/10.1037/ a0029393

Seo, Y.W., Lee, K.C., \& Lee, S. (2017). Decision quality of the research project evaluation mechanism by using particle swarm optimization. Management Decision, 55(4) 745-765. https://doi.org/10.1108/MD-03-2016-0141

Shepherd, D.A., \& Baron, R.A. (2013). 'I care about nature, but ...': Disengaging values in assessing opportunities that cause harm. Academy of Management Journal, 56(5), 1251-1273. https://doi.org/10.2307/43589216

Shortland, N., \& Alison, L. (2020). Colliding sacred values: A psychological theory of least-worst option selection. Thinking \& Reasoning, 26(1), 118-139. https://doi. org//10.1080/13546783.2019.1589572

Stephan, U. (2020). The value of values for understanding organizational life: Editor's introduction to the lead article. Applied Psychology: An International Review, 69(2), 223-229. https://doi.org/10.1111/apps.12213

Tamir, M., Cieciuch, J., Torres, C., Dzokoto, V., Schwartz, S.H., Riediger, M., ... Vishkin, A. (2016). Desired emotions across cultures: A value-based account. Journal A. (2016). Desired emotions across cultures: A value-based account. Journal
of Personality and Social Psychology, 111(1), 67-82. https://doi.org/10.1037/ of Personality

Tetlock, P.E. (1986). A value pluralism model of ideological reasoning. Journal of Personality and Social Psychology, 50(4), 819-827. https://doi.org/10.1037/00223514.50.4.819

Uhl-Bien, M., \& Arena, M. (2018). Leadership for organizational adaptability: A theoretical synthesis and integrative framework. Leadership Quarterly, 29(1), 89-104. https://doi.org/10.1016/j.leaqua.2017.12.009

Vecchione, M., Alessandri, G., Barbaranelli, C., \& Caprara, G. (2011). Higher-order factors of the big five and basic values: Empirical and theoretical relations. British Journal of Psychology, 102(3), 478-498. https://doi.org/10.1111/j.20448295.2010.02006.x

Vecchione, M., Schwartz, S.H., Caprara, G.V., Schoen, H., Cieciuch, J., Silvester, J., ... Alessandri, G. (2015). Personal values and political activism: A cross-national study. British Journal of Psychology, 106(1), 84-106. https://doi-org.uplib.idm. oclc.org/10.1111/bjop.12067

Visinescu, L.L., Jones, M.C., \& Sidorova, A. (2017). Improving decision quality: The role of business intelligence. Journal of Computer Information Systems, 57(1), 58-66. https://doi.org/10.1080/08874417.2016.1181494

Wanous, J.P., \& Youtz, M.A. (1986). Solution diversity and the quality of group decisions. Academy of Management Journal, 29(1), 159-169. https://doi. org $/ 10.2307 / 255866$

Warnock, S., \& Gantz, J.S. (2017). Gaming for respondents. A test of the impact of gamification on completion rates. International Journal of Market Research, 59(1), 117-137. https://doi.org/10.2501/IJMR-2017-005

White, C.N., \& Poldrack, R.A. (2014). Decomposing bias in different types of simple decisions. Journal of Experimental Psychology: Learning, Memory \& Cognition, 40(2), 385-398. https://doi.org/10.1037/a0034851

Woehr, D., Arciniega, L., \& Poling, T. (2013). Exploring the effects of value diversity on team effectiveness. Journal of Business \& Psychology, 28(1), 107-121. https://doi. org $/ 10.1007 / \mathrm{s} 10869-012-9267-4$ 